\title{
Fibroadnexal hamartoma in the dog: retrospective epidemiological and histopathological study of 102 cases
}

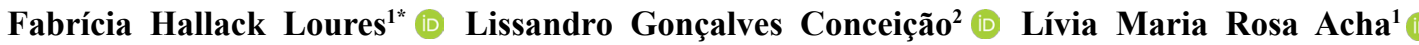 \\ 'Programa de Pós-Graduação em Medicina Veterinária, Universidade Federal de Viçosa (UFV), 36570-900, Viçosa, MG, Brasil. E-mail: \\ fabriciadermatopato.vet@gmail.com. .Corresponding author. \\ ${ }^{2}$ Departamento de Veterinária, Universidade Federal de Viçosa (UFV), Viçosa, MG, Brasil.
}

\begin{abstract}
Fibroadnexal hamartoma (FH), also called focal adnexal dysplasia, is the most common hamartomatous lesion in dogs. There are few retrospective studies about FH in dogs, which did not describe histopathological findings in detail. The main objective was to conduct a retrospective study and to describe the epidemiological and histopathological characteristics of a series of $102 \mathrm{FH}$ cases in dogs. Descriptive statistics and Odds Ratio were used to analyze the data. The lesions were exophytic and measured on average $2.5 \mathrm{~cm}$ in diameter. The anatomic sites most affected were the limbs and digital region. The animals were on average 7 years of age and both sexes were equally affected. Doberman (OR: 4.15; $P=0.0069)$ and Schnauzer (OR: 2.50; $P=0.049$ ) showed a higher risk for FH. Recurrence was not observed in any case. Four histopathological FH subtypes were identified: follicle-sebaceous (73.53\%), sebaceous (16.66\%), follicular (8.82\%) and sebaceousapocrine $(0.98 \%)$. Diffuse and perianexial fibroplasia and inflammation were frequently seen. Chronic inflammation and mature adipocytes were seen in $71.6 \%$ and $7.8 \%$ of the cases, respectively.
\end{abstract}

Key words: fibroadnexal hamartoma, nevus, dog.

Hamartoma fibroanexial em cão: estudo retrospectivo epidemiológico e histopatológico de 102 casos

RESUMO: Hamartoma fibroanexial (HF), também denominado displasia focal anexial, é a lesão hamartomatosa mais comum em cães. Existem poucos estudos retrospectivos sobre HF em cães, os quais não descrevem detalhadamente os achados histopatológicos. O objetivo principal foi realizar um estudo retrospectivo e descrever as características epidemiológicas e histopatológicas de uma série de 102 casos de HF em cães. A estatística descritiva e Odds Ratio foram utilizadas para a análise dos dados. As lesões foram exofiticas e mediram em média $2,5 \mathrm{~cm}$ de diâmetro. Os locais anatômicos mais acometidos foram os membros e digitos. Os animais tinham em média 7 anos de idade e ambos os sexos foram igualmente acometidos. Doberman (OR: 4.15; $P=0,0069)$ e Schnauzer (OR: 2,50; $P=0,049)$ mostraram-se com maior risco para o HF. Não foi relatada recorrência para nenhum caso. Quatro subtipos histopatológicos de HF foram identificados: folículosebáceo (73,53\%), sebáceo (16,66\%), folicular (8,82\%) e sebáceo-apócrino (0,98\%). Fibroplasia difusa e perianexial e inflamação foram frequentemente observadas. Inflamação crônica e adipócitos maduros foram vistos em 71,6\% e 7,8\% dos casos, respectivamente. Palavras-chave: hamartoma fibroanexial, nevo, cão.

\section{INTRODUCTION}

Nevi (Latin Naevus: birthmark) is an encircled and stable malformation of the skin, probably congenital, characterized by the focal excess of one or several mature tissue components (MEHREGAN, 1986; GOLDSCHMIDT \& SHOFER, 1992). The meaning of the hamartoma is similar to nevi, but the former is related to a lesion which tends to deviate from the normal histological structure, whose components are not necessarily mature and may show a more extensive growth (MEHREGAN, 1986; WALDER \& GROSS, 1992).

Fibroadnexal hamartoma (FH) is a common nonneoplastic lesion of adnexal appendages reported to comprise $2,7 \%$ of all canine skin tumors (GROSS et al., 2005), and $25 \%$ of all canine tumor-like lesions (GOLDSCHMIDT \& SHOFER, 1992). The FH are typically solitary, firm, circumscribed and dome-shaped to polypoid masses that range from approximately $1 \mathrm{~cm}$ to more than $4 \mathrm{~cm}$ in diameter. Smaller lesions may have partial alopecia, while larger lesions frequently exhibit alopecia and ulceration. The FH occurs most commonly on the distal legs, pressure points and interdigital areas. Lesions were less frequently on head and trunk. Animals are generally middle-aged or older, range of 2 to 16 years (GROSS et al., 2005). Large breed dogs, particularly Labrador Retriever, Weimaraner, Dalmatian and Doberman Pinscher, appear to be predisposed (GOLDSCHMIDT \& SHOFER, 1992). 
There are few retrospective studies about FH in dogs (GOLDSCHMIDT \& SHOFER, 1992; LOURES \& CONCEIÇÃO, 2009), which did not describe histopathological findings in detail. Therefore, this paper describes both epidemiological and histopathological findings in 102 cases of canine $\mathrm{FH}$.

\section{MATERIALS AND METHODS}

In a period of seven years, a retrospective study was carried out on file archives of all cases of cutaneous biopsies of the pathology service. Those diagnosed as FH were selected along with their H\&E stained histological slides. The selected cases were blindly reviewed by two pathologists for diagnostic confirmation and histopathological description. Information regarding breed, age and sex of the animals, anatomical location, number and size of the lesions was obtained from medical records. Time of evolution of the lesions was determined from the moment the lesion was initially observed until the surgical procedure. Clinical and epidemiological information were not available for all 102 cases; therefore, the number of cases whose such data was retrieved is indicated by " $(\mathrm{n}=\mathrm{x})$ ". The histological slides of all FH cases were re-evaluated under light optical microscopy, regarding changes in the epidermis, adnexa, dermis and panniculus. For data analysis descriptive statistic was used; empirical frequency distribution and histogram for qualitative and quantitative variables, respectively. The Odds Ratio with a $95 \%$ confidence interval was calculated to determine breed predisposition (https://www. medcalc.org/calc/odds-ratio.php).

\section{RESULTS AND DISCUSSION}

Out of a total of 5864 canine skin biopsies, $102(1.7 \%)$ were diagnosed as FH. Fifty-nine cases $(57.8 \%)$ occurred in males and 43 cases $(42.1 \%)$ in females $(n=102)$. The male: female ratio was $1.4: 1$. In a large retrospective study, the male: female ratio was 0.83:1 (GOLDSCHMIDT AND SHOFER, 1992) and the two genders appear to be equally affected by $\mathrm{FH}$.

Lesions were predominantly solitary, with only four cases $(5.0 \%)$ showing more than one lesion $(\mathrm{n}=80)$. In these cases, a histopathologic examination was performed for all lesions, confirming the diagnosis of FH. The frequency of animals with multiple lesions was higher than previously described (1\%) (GOLDSCHMIDT \& SHOFER, 1992). Number of lesions was related to the nature of the predisposing dermatosis (YAGER \& WILCOCK, 1994); however, in the present study only one animal with multiple nodules in the external ear canal had chronic inflammatory disease associated with $\mathrm{FH}$ (chronic external otitis).

All lesions were exophytic. Forty-one $(75,9 \%)$ and 13 cases $(24,1 \%)$ had smooth and irregular surfaces, respectively $(n=54)$. All lesions were referred to have a firm consistence $(n=27)$. Alopecia was present in 29 cases $(49,1 \%)(n=59)$, and pruritus in 40 cases $(74 \%)(n=54)$. In canine $\mathrm{FH}$, pruritus was not previously reported, but in the present study, it was a frequent sign; this could be a result of the chronic inflammatory reaction which was present in many lesions. The average size of the lesions was $2.5 \mathrm{~cm}$ in diameter, ranging from $5 \mathrm{~mm}$ to $8 \mathrm{~cm}(\mathrm{n}=85)$ (Table 1); this wide variation in diameter was also reported in the literature.

Lesions were mainly found on the legs, digits and interdigital region (Figure 1 and Table 2). A higher frequency of lesions on the legs and digits was also reported in other study (GOLDSCHMIDT \& SHOFER, 1992) and could point towards a traumatic etiology. Many cases of FH occurred at sites where the sebaceous glands tend to be larger and more numerous than at other sites, such as the leg extremities, digits and interdigital regions.

The average age of the affected animals was 7.52 years, ranging from 1 to 14 years $(n=76)$ (Figure 2). The FH occurred mainly in adult dogs, with most cases $(86,8 \%)$ occurring in animals over 5 years of age. However, the dense hair coat of some animals could have masked small and non-elevated lesions, hindering early detection (GROSS et al., 2005).

The breeds affected more frequently by FH were mixed breed, Boxer, Cocker Spaniel, Labrador Retriever, German Shepherd, Schnauzer, Poodle and Doberman. However, only Doberman (OR: 4.15; $\mathrm{P}=0.0069)$ and Schnauzer (OR: 2.50; $\mathrm{p}=0.049$ ) were at greater risk (Table 3 ). In another

Table 1 - Canine fibroadnexal hamartoma. Frequency of occurrence relative to the size of the lesions $(\mathrm{n}=85)$.

\begin{tabular}{|lc}
\hline Size $(\mathrm{cm})$ & Number of the lesions $(\%)$ \\
\hline $0-1$ & $12(14.1)$ \\
$1-2$ & $32(37.6)$ \\
$2-3$ & $25(29.4)$ \\
$3-4$ & $7(8.2)$ \\
$4-5$ & $4(4.8)$ \\
\hline above 5 & $5(5.9)$ \\
\hline
\end{tabular}




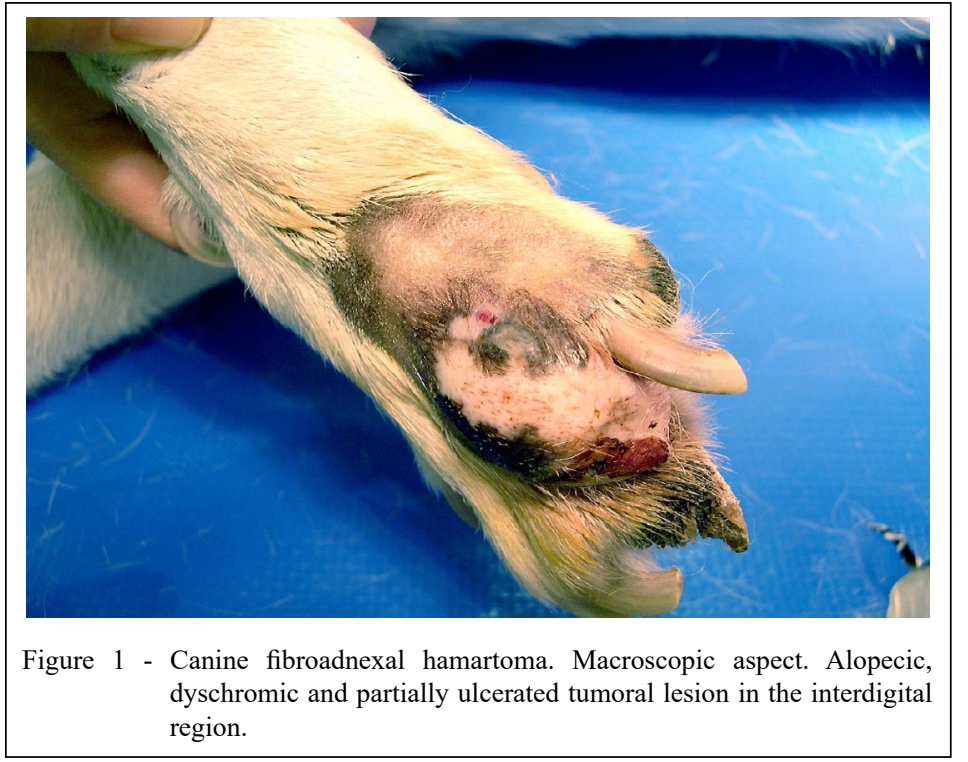

study, Labrador Retriever, Doberman Pinscher, Weimaraner and Dalmatian were at greater risk of $\mathrm{FH}$ (GOLDSCHMIDT \& SHOFER, 1992). Schnauzer was not considered predisposed to $\mathrm{FH}$ development in previous report.

The time of clinical evolution for $\mathrm{FH}$ ranged from 1 month to 5 years with an average of 12.6 months. In a follow up of 3 to 36 months after surgical excision, no lesion recurrence was observed. No information about recurrence was reported in the literature.

Histopathologically, FH was characterized by one or more bizarre adnexal units, variable

Table 2 - Canine fibroadnexal hamartoma. Frequency of occurrence relative to the anatomical site $(n=75)$.

\begin{tabular}{lc}
\hline Site & Number of animals $(\%)$ \\
\hline Legs & $37(49.3)$ \\
front & $15(20.0)$ \\
hind & $20(26.7)$ \\
\hline no information & $2(2.7)$ \\
\hline Digit/interdigital & $13(17.3)$ \\
Trunk back & $6(8.0)$ \\
Cervical & $5(6.7)$ \\
\hline Head & $5(6.7)$ \\
\hline Abdomen (lateral) & $3(4.00)$ \\
Lateral trunk & $2(2.7)$ \\
Perianal & $2(2.7)$ \\
Tail & $1(1.3)$ \\
\hline Preputial sheath & $1(1.3)$ \\
\hline
\end{tabular}

fibroplasia and inflammation. In this study, according to adnexal morphology, four histopathological $\mathrm{FH}$ subtypes were identified: follicle-sebaceous ( 75 cases $73,53 \%)$, sebaceous (17 cases - 16,66\%), follicular (9 cases - 8,82\%) and sebaceous-apocrine ( 1 case - $0,98 \%$ ). Predominance of the aberrant proliferation of sebaceous lobes and ducts, the main component of sebaceous-like lesions, was also mentioned in the literature (YAGER \& WILCOCK, 1994). Conversely, follicular and aposebaceous variants have not been previously reported. Thus, FH lesions may involve one or more types of epidermal adnexal, in different patterns, and not just the classic follicle-sebaceous type.

The hair follicles showed bizarre morphology with enlargement, tortuosity, hyperplasia and follicular hyperorthokeratosis (Figure 3). Orientation of the hair follicles regarding skin surface was also analyzed. It was parallel in 23 cases $(22.5 \%)$ of the cases, oblique in 14 cases $(13.7 \%)$ and perpendicular in 9 cases $(8,8 \%)$. In 56 cases $(55 \%)$ a combination of two or three orientations was seen. These follicular orientations were also described in previous studies (GOLDSCHMIDT \& SHOFER, 1992; WALDER \& GROSS, 1992; YAGER \& WILCOCK, 1994). The predominance of parallel and oblique arrangement may be a consequence of the chronic effect of mechanical pressure on the lesions, often located at the pressure points.

The so-called giant hair follicle disease (nevi composed of giant hair follicles - GHFD) is considered by some authors as being a distinct entity from FH (YAGER \& WILCOCK, 1994). In this study, nine cases $(8,8 \%)$ had hyperplasic hair follicles in the lesion periphery, compatible with GHFD. 


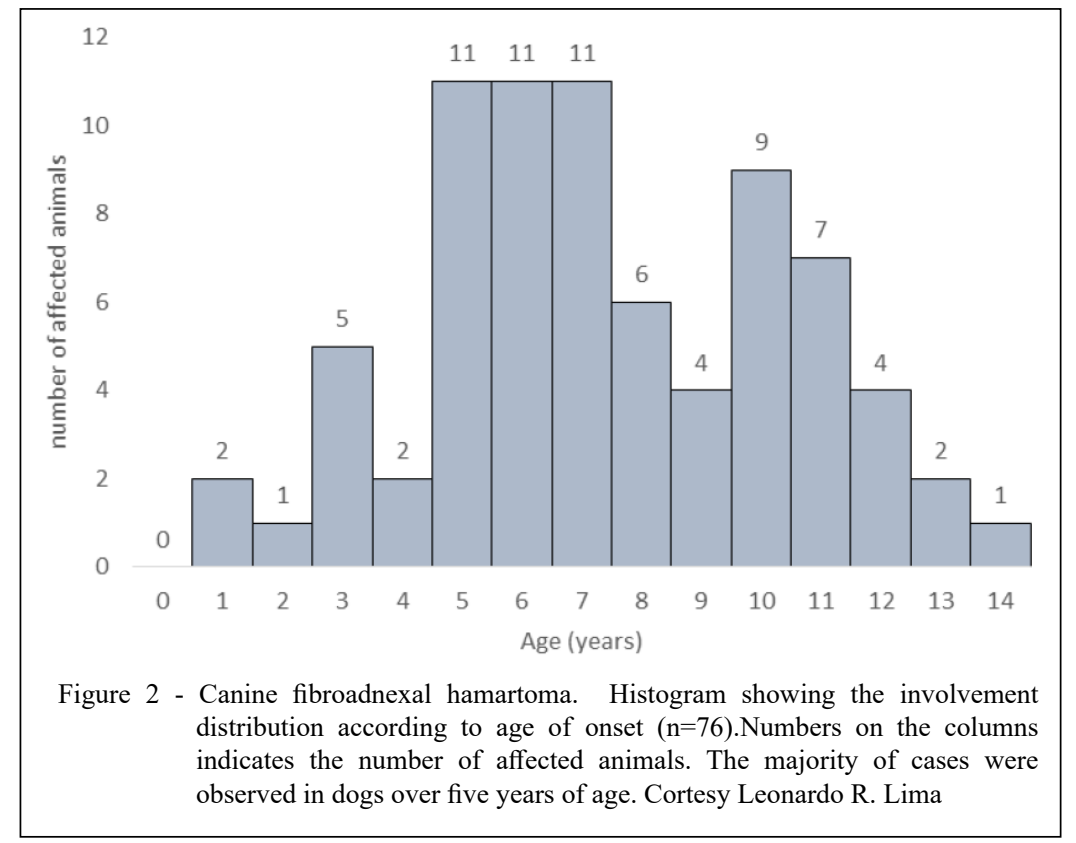

These findings suggested that GHFD and FH could indeed represent different stages within a spectrum of the same pathological process.

The sebaceous glands frequently had geographical contours and were haphazardly arranged around the hair follicles; they were often hyperplastic with dilated ducts. Orphan sebaceous glands (dissociated from the follicular infundibulum) were reported in 33 cases (32.3\%). The presence of isolated sebaceous gland may proliferate resulting in a sebaceous-rich histopathological type (YAGER \& WILCOCK, 1994). Sweat apocrine glands were seen in 41 cases $(40.2 \%)$. They were enlarged and hyperplasic in 10 cases $(24.4 \%)$. Irregular epidermal hyperplasia and hyperorthokeratosis were the dominant superficial changes. Few comments have been made in the literature about the epidermal alterations, mentioning only acanthosis and ulceration

Table 3 - Canine fibroadnexal hamartoma. Odds Ratio of the breeds more affected by fibroadnexal hamartoma. "Doberman and Schnauzer were at increased risk for the hamartoma development.

\begin{tabular}{llc}
\hline Breeds & P value & Odds Ratio \\
\hline Mixed breed & 0.1912 & 1.3995 \\
\hline Boxer & 0.1230 & 1.6469 \\
\hline Cocker Spaniel & 0.2247 & 1.4803 \\
\hline Labrador Retriever & 0.1119 & 1.7558 \\
\hline German Shepherd & 0.3335 & 1.5101 \\
${ }^{*}$ Schnauzer & 0.0494 & 2.5089 \\
\hline Poodle & 0.0704 & 0.4346 \\
\hline Dobermann Pinscher & 0.0069 & 4.1589 \\
\hline Beagle & 0.1706 & 2.2671 \\
\hline Great Dane & 0.1085 & 2.6152 \\
\hline Rottweiler & 0.7992 & 0.8605 \\
\hline Weimaraner & 0.0780 & 2.8798 \\
\hline Yorkshire & 0.6556 & 1.3026 \\
\hline Daschund & 0.9299 & 0.9557 \\
\hline
\end{tabular}




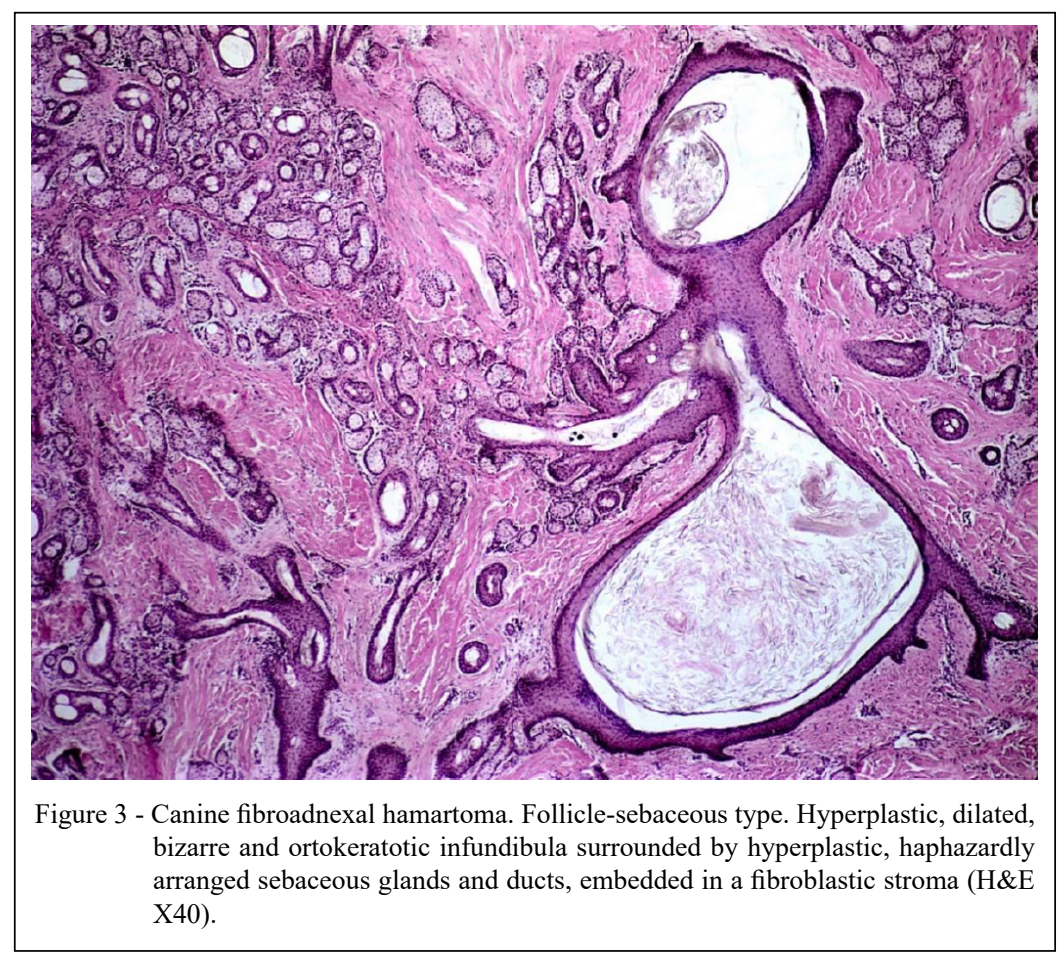

(GOLDSCHMIDT \& SHOFER, 1992; WALDER \& GROSS, 1992; GROSS et al., 2005).

In all cases the lesions were localized throughout the dermis (Table 4), but none of them involved only the superficial dermis, as described previously (YAGER \& WILCOCK, 1994). Because of the intense dermal fibroplasia and adnexal dysplasia, normal adnexal structures were displaced to the tissue periphery in 25 cases $(24,5 \%)$.

The etiology of FH remains controversial. A scarring reaction, after chronic inflammation, could involve and distort the follicle-sebaceous units. The high frequency of $\mathrm{FH}$ over pressure points, along with fibroplasia and inflammatory reaction,

Table 4 - Canine fibroadnexal hamartoma. Histopathological findings. Level of dermal involvement by hamartomatous proliferation $(n=102)$.

\begin{tabular}{lc}
\hline Dermal localization & Number of cases (\%) \\
\hline Full dermis & $49(48.0)$ \\
Medium dermis & $13(12.7)$ \\
\hline Superficial and médium dermis & $30(29.4)$ \\
Medium and deep dermis & $6(5.9)$ \\
Deep only & $4(3.9)$ \\
Superficial only & $0(0)$ \\
\hline
\end{tabular}

gives support to this etiopathogenesis (WALDER \& GROSS, 1992; GROSS et al., 2005). It is likely that the predominance of mononuclear cells in the periadnexal dermis represents an advanced stage of previous folliculitis and furunculosis (WALDER \& GROSS, 1992; YAGER \& WILCOCK, 1994; GROSS et al., 2005). In the present study, chronic inflammation occurred in 73 cases $(71.6 \%)$ (Table 5). Diffuse and perianexial fibroplasia and inflammation were frequently seen. The periadnexal inflammatory

Table 5 - Canine fibroadnexal hamartoma. Histopathological findings. Distribution of histopathological inflammatory pattern $(\mathrm{n}=73)$.

\begin{tabular}{lc}
\hline Type of the inflammatory pattern & Number of cases (\%) \\
\hline Periadnexal $(\mathrm{Pa})$ & $12(16.4)$ \\
\hline Furunculosis $(\mathrm{Fu})$ & $10(13.7)$ \\
Nodular $(\mathrm{N})$ & $5(6.9)$ \\
\hline Diffuse & $1(1.3)$ \\
\hline Perivascular $(\mathrm{Pv})$ & $11(15.1)$ \\
Mixed pattern & $34(46.6)$ \\
$\mathrm{Pa}$ and Fu & $14(19.2)$ \\
$\mathrm{Pa}$ and $\mathrm{N}$ & $2(2.8)$ \\
\hline $\mathrm{Pa}$ and $\mathrm{Pv}$ & $3(4.1)$ \\
\hline two or more patterns & $15(20.5)$ \\
\hline
\end{tabular}

Ciência Rural, v.49, n.9, 2019. 
reaction was composed mostly by lymphocytes, plasma cells and histiocytes. In 36 cases (35.3\%), furunculosis was observed accompanied by pyogranulomatous inflammation. Subcutaneous pannicular tissue was inflamed and fibrotic in 13 cases $(12,7 \%)$. In addition, a mucinoid matrix associated with perianexial fibroplasia was reported in nine cases $(8.8 \%)$. A vascular rich stroma in the adventitial dermis (superficial and periadnexal) is probably the cause for this adnexocentric inflammatory response.

However, small lesions may show no inflammation and unequivocal distortion of the adnexal structures (WALDER \& GROSS, 1992; GROSS et al., $2005)$. In this series of cases, $29(28,4 \%)$ did not show any sign of inflammation. Therefore, inflammation alone cannot be the only cause for FH development. Additionally, several other dermatoses characterized by chronic dermal inflammation and dermal fibrosis do not show distortion of the pilosebaceous units. Furthermore, the so-called folliculosebaceous cystic hamartoma (FSCH) in humans, which is histologically very similar to canine $\mathrm{FH}$, usually has no stromal inflammation (ACKERMAN et al., 2001; CALONJE et al., 2012). So, the pathogenesis of FH may require some unknown factor, such as breed or individual predisposition, to result in folliclesebaceous alterations (WALDER \& GROSS, 1992). A congenital or acquired defect in the regulation of skin structure development, possibly an excess of growth factors, could also be involved in the pathogenesis (YAGER \& WILCOCK, 1994). Interestingly, in 8 cases $(7.8 \%)$ mature adipocytes were associated with the bizarre adnexa in the dermis (Figure 4). It is possible that under the action of selective growth factors, multipotent precursor dermal cells differentiate in distinct cells types, resulting in excess of one or more tissue components of the skin.

Comparatively, the FSCH in humans are very similar to canine $\mathrm{FH}$. In both conditions the lesions are located in the dermis and also in the subcutaneous tissue, with large and bizarre hair follicles, infundibular cysts nearby to numerous sebaceous gland lobules and surrounded by intense fibroplasia. The vascular proliferation, occasional mucinoid stroma, adipocytes and the absence of hair erector muscle are other common characteristics between the human FSCH and canine FH (ACKERMAN et al., 2001; DAROUTY et al., 2001). However, unlike canine FH, human FSCH has a highly fibrocytic stroma well delimited from the adjacent dermis by clefts. In addition, epidermal involvement and inflammatory infiltrate in the dermis are not usually observed in human disease. Those two differences are probably explained by the fact that human $\mathrm{FSCH}$ are asymptomatic and not traumatized as the canine counterpart.

Other histopathologic diagnoses associated with $\mathrm{FH}$ occurred in $12(11.7 \%)$ of the cases. Infundibular follicular cysts were the most prevalent and no such information could be found in the literature. Also, concomitant finding of infundibular cysts could point to trauma as a possible unifying cause.

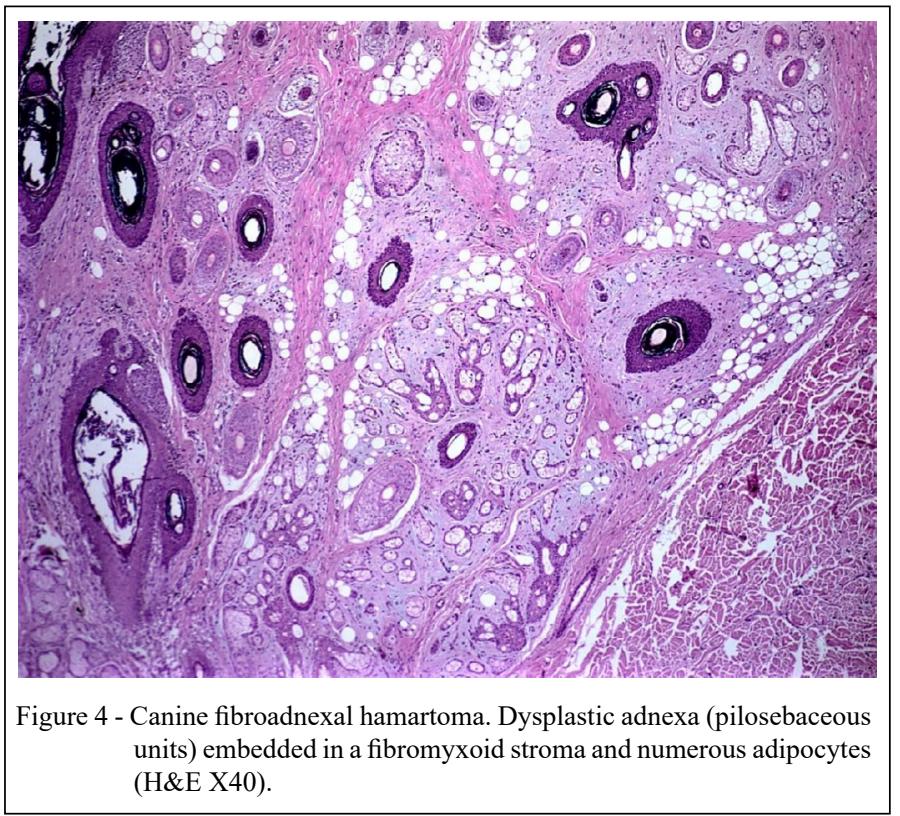

Ciência Rural, v.49, n.9, 2019. 
Finally, different names are reported in the literature for this pathologic condition: adnexal nevus, focal adnexal dysplasia, folliculosebaceous hamartoma, fibroadnexal dysplasia and fibroadnexal hamartoma (GOLDSCHMIDT \& SHOFER, 1992; WALDER \& GROSS, 1992; GROSS et al., 2005; MILLER et al., 2013). Hamartoma is the term that better defines these lesions, since the normal histological architectural arrangement is replaced by hyperplastic and bizarre adnexal structures. Therefore, the unified nomenclature of fibroadnexal hamartoma is encouraged, since it describes both fibroplastic and hyperplastic/dysplastic adnexal changes.

\section{CONCLUSION}

Canine FH was characterized clinically by nodular lesions that were usually singular and firm, located especially on the limbs and digits, without gender predisposition. Doberman and Schnauzer were at increases risk for $\mathrm{FH}$ development. Lesions occur in middle aged dogs and no gender predilection was observed. The FH lesions was more prevalent in legs and interdigital space. Most of the lesions were between 1 and $3 \mathrm{~cm}$ in diameter. Histopathologically, FH presented as one or more hyperplastic/dysplastic adnexal units, with fibroplasia and variable patterns of inflammation. Different histopathological types can be identified according to the cutaneous components involved in the hamartomatous process.

\section{ACKNOWLEDGEMENTS}

This study was financed in part by the Coordenação de Aperfeiçoamento de Pessoal de Nível Superior (CAPES), Brasil - Finance code 001.

\section{DECLARATION OF CONFLICT OF INTERESTS}

The authors declare no conflict of interest. The founding sponsors had no role in the design of the study; in the collection, analyses, or interpretation of data; in the writing of the manuscript, and in the decision to publish the results.

\section{AUTHORS' CONTRIBUTIONS}

All authors contributed equally for the conception and writing of the manuscript. All authors critically revised the manuscript and approved the final version.

\section{REFERENCES}

ACKERMAN, A.B., et al. Folliculo-sebaceous cystic hamartoma. In: Ackerman's histologic diagnosis of neoplastic skin diseases: a method by pattern analysis. Neoplasms with follicular differentiation. 2.ed. USA:Ardor Scribendi Publishers, 2001. Cap.20, p.191-208.

CALONJE, E., et al. Tumors of the hair follicle. In: Mckee's pathology of the skin with clinical correlations. 4.ed. Saunders, 2012. Cap.31, p.1445-1487.

DAROUTY, T.A. et al. Folliculo-sebaceous cystic hamartoma. International Journal of dermatology, v. 40, n. 7, p.454-457. Available from: <https://onlinelibrary.wiley.com/doi/epdf/10.1 046/j.1365-4362.2001.01245.x>. Accessed: Feb. 16, 2019. doi: 10.1046/j.1365-432.2001.01245.x.

GOLDSCHMIDT, M.H.; SHOFER, F.S. Nevi and skin tags. In: Skin tumors of the dog and cat. 1.ed. Great Britain|: Pergamon Press, 1992. Cap.32, p.284-290.

GROSS, T.L., et al. Follicular tumors. In: Skin diseases of the dog and cat. Clinical and histopathologic diagnosis. 2.ed. Oxford:Blackwell Science, 2005. Cap.23, p.604-640.

LOURES, F.H.; CONCEIÇÃO, L.G. Nevi and cutaneous hamartomas in dogs: retrospective clinical and epidemiologic study of 81 cases. Ciência Rural, Santa Maria, v.39, n.9, 2009. Available from: <http://www.scielo.br/scielo.php?pid=S0103$84782009000900022 \&$ script $=$ sci arttext $>$. Accessed: Jan. 1, 2019. doi: 10.1590/S0103-84782009000900022.

MEHREGAN, A.H. Pinku's guide to dermatohistopathology. 4.ed. Norwalk: Appleton-Century-Crofts, 1986. 1v.

MILLER, W.H.; GRIFFIN, C.E.; CAMPBELL, K.L. Neoplastic and non-neoplastic tumors. In: _. Muller and kirk's small animal dermatology. 7.ed. St Louis: Elsevier, 2013. Cap.20, p.774-843.

WALDER, E.J.; GROSS, T.L. Focal adnexal dysplasia (Folliculosebaceous hamartoma). Advances in veterinary dermatology. In: WORLD CONGRESS OF VETERINARY DERMATOLOGY, 2., 1992, Montreal. Proceedings... Montreal, 1992. V.2. p. 311-13.

YAGER, J.A.; WILCOCK, B.P. Other proliferative lesions. In: Color atlas and text of surgical pathology of the dog and cat: Dermatopathology and skin tumors. 1.ed. London: Wolfe Publishing, 1994. Cap.22, p.311-313. 